\title{
Polymorphous Low-Grade Adenocarcinoma of Submandibular Gland
}

\author{
Ali Akhavan ${ }^{1}$; Fariba Binesh ${ }^{2,}$; Reza Nafis Moghadam ${ }^{3}$ \\ ${ }^{1}$ Department of Radiation Oncology, Isfahan University of Medical Sciences, Isfahan, IR Iran \\ ${ }^{2}$ Department of Pathology, Shahid Sadoughi University of Medical Sciences, Yazd, IR Iran \\ ${ }^{3}$ Department of Radiology, Shahid Sadoughi University of Medical Sciences, Yazd, IR Iran \\ *Corresponding author: Fariba Binesh, Department of Pathology, Shahid Sadoughi University of Medical Sciences, Yazd, IR Iran. Tel: +98-351-3183698, \\ Fax: +98-351-3183698, E-mail: binesh44@yahoo.com \\ Received: May 4, 2014; Revised: August 24, 2014; Accepted: September 15, 2014
}

\begin{abstract} major salivary gland origin. large firm and non-tender mass was palpable in the submandibular region. irregular enhancement in the submandibular gland.

Keywords: Adenocarcinoma; Submandibular Gland; Woman

1. Introduction

Polymorphous low-grade adenocarcinoma (PLGA) is a rare malignant tumor which mostly develops in minor salivary glands (1). PLGA accounts for $7-11 \%$ of all benign and malignant neoplasms and about $19-26 \%$ of all malignancies in minor salivary glands (2). The palate is the most frequent location of PLGA. The appearance of PLGA in major salivary glands is extremely rare, and it has only been referenced in a few reports (3-5). A correct differential diagnosis is particularly important because treatment and prognosis are different.
\end{abstract}

Introduction: Polymorphous low-grade adenocarcinoma (PLGA) occurs mostly in minor salivary glands, and there are only a few reports of

Case Presentation: We herein report a case of de novo PLGA arising in a submandibular gland in an 88 years old woman. On examination, a

Conclusions: Neither lymphadenopathy nor enlargement of any other salivary glands was present. CT showed a well-defined mass with

\section{Case Presentation}

An 88 years old woman residing in Iran was referred to the ENT Surgery Clinic of Shahid Sadoughi Hospital in April 2013 with a symptom of swelling in the left submandibular region. She had first noticed the swelling approximately 5 years earlier and it had gradually enlarged thereafter. On examination, a large firm and non-tender mass was palpable in the submandibular region. Neither lymphadenopathy nor enlargement of any other salivary glands was present. CT showed a well-defined mass with irregular enhancement in the submandibular gland (Figure 1). Magnetic resonance imaging (MRI) demonstrated that the mass had a low signal on T1-, a low to isosignal on T2-weighted images in the left submandibular region involved the left aspects of tongue, oropharynx, mandibular ramous, and body, infratemporal fossa, maxil- lary bone, alveolar ridge, temporalis muscle, and carotid space. After an injection of gadolinium the tumor showed marked non-homogeneous enhancement. The clinical diagnosis was suspected PA. An incisional biopsy was performed. Histopathologic examination revealed that tumor cells had mainly tubular patterns and consisted of isomorphic epithelial cells having round to oval nuclei with non-prominent nucleoli. Mitotic features were rare. Necrotic areas and perineural and vascular invasion were not observed. The tumor stroma showed myxoid changes with focal lymphocyte infiltration (Figure 3). The tumor was positive for AE1/AE3, vimentin and S-100 protein. CEA was partially positive. The Ki-67 labeling index was $20 \%$. The pathologic diagnosis was polymorphous low-grade adenocarcinoma. Since the mass was very large and needed an extensive surgical procedure, the ENT surgeons decided to refer the patient for definitive radiation therapy. The patient treated with two parallel opposed lateral fields according to tumor volume showed by MRI and at least $2 \mathrm{~cm}$ margins from each side that finally became a $12 \times 12 \mathrm{~cm}$ field with photon $6 \mathrm{MV}$. This field encompassed levels I and II and the upper part of level III of lymph nodes on the neck. After 4500 cGy the field shrank to $10 \times$ $11 \mathrm{~cm}$ and the patient received more $2000 \mathrm{cGy}$ to a total of 6500 cGy final dose. Physical examination 8 weeks later showed no evidence of previous mass and repeated MRI 12 weeks after termination of radiation therapy showed an excellent tumor response.

Copyright (C) 2015, Iranian Society of Clinical Oncology. This is an open-access article distributed under the terms of the Creative Commons Attribution-Non Commercial 4.0 International License (http://creativecommons.org/licenses/by-nc/4.0/) which permits copy and redistribute the material just in noncommercial usages, provided the original work is properly cited. 

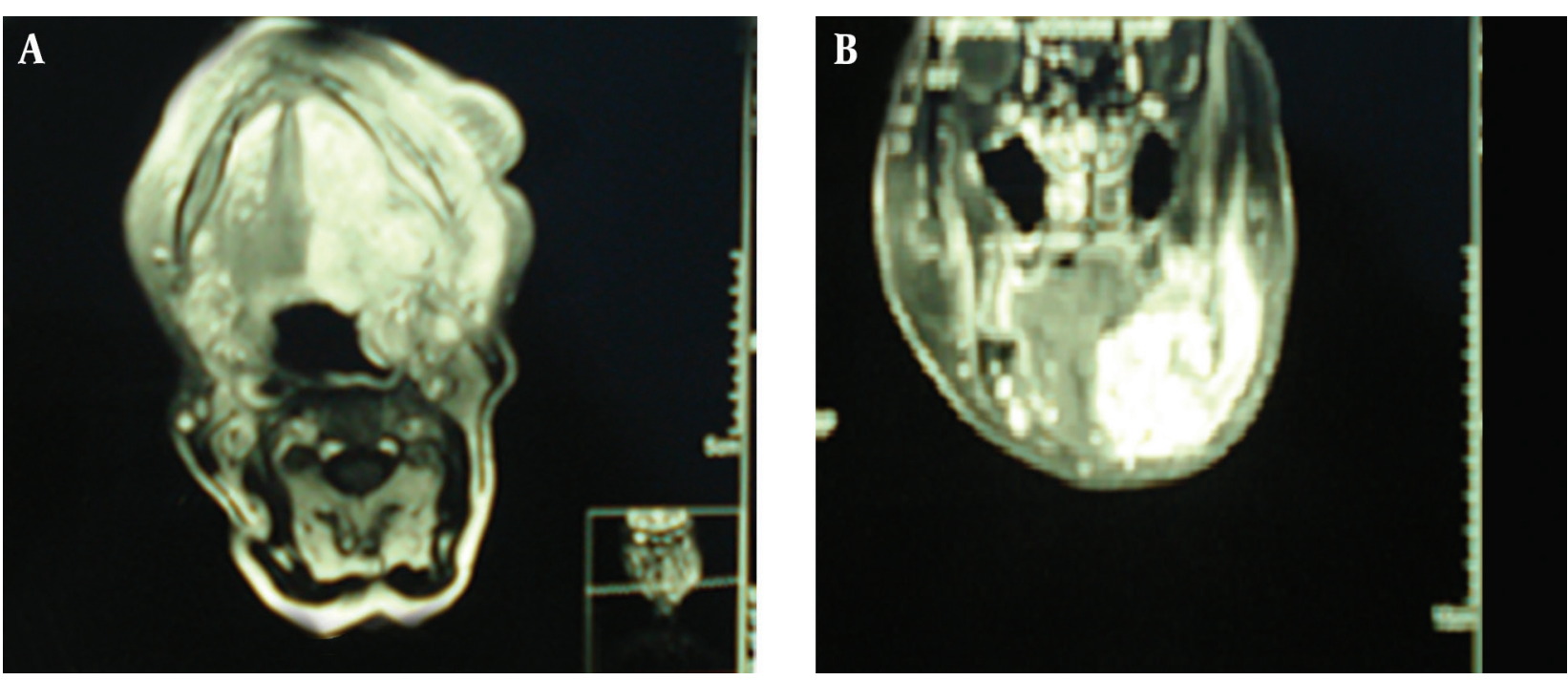

Figure 1. A, B: MRI Showed a Well-Defined Mass With Irregular Enhancement in the Submandibular Gland

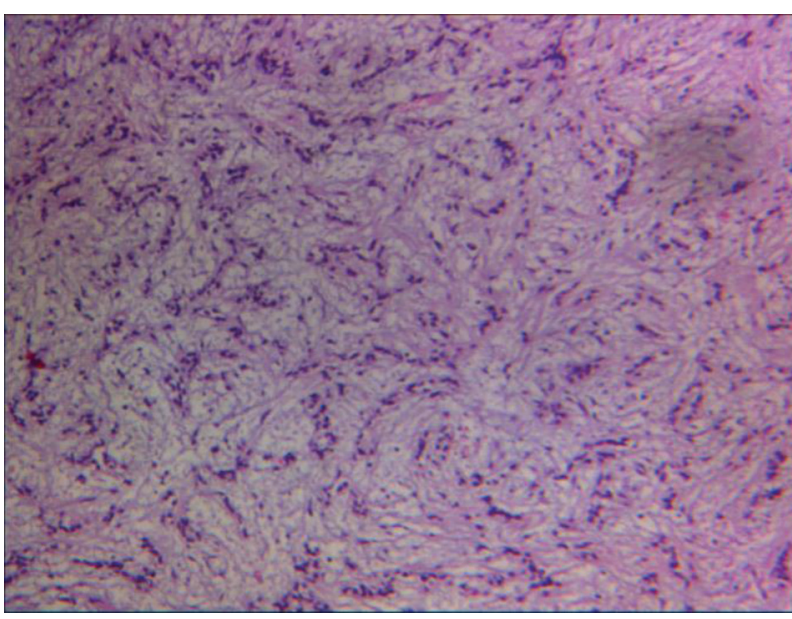

Figure 2. Section Showed Isomorphic Epithelial Cells With Round to Oval Nuclei With Non-Promiment Nucleoli, Mitotic Features Were Rare (H\&E $\mathrm{x} 10)$

\section{Discussion}

First appearing in the second edition of the WHO Classification of Salivary Tumours in 1991 (6), PLGA was initially described in 1983 by Batsakis et al. and Freedman et al. $(7,8)$. Only pleomorphic adenoma and mucoepidermoid carcinoma are more common than polymorphous low-grade adenocarcinoma, and it is twice as frequent as adenoid cystic carcinoma (9). It has been reported to exhibit a nearly 2:1 female-to-male ratio and a wide age range (16 - 94 years) with a mean of 59 years (10). Our patient was an 88 years old woman. PLGA is generally an asymptomatic, slowly growing mass or swelling of the palate, cheek, or upper lip. Multiple synchronous occurrences have been reported (11). The present case had first noticed the swelling approximately 5 years earlier, and it had gradually enlarged thereafter. Most PLGAs will not cause diagnostic difficulty if careful attention is paid to the lack of pleomorphism and arrangement of the tumor cells. However, occasional tumors may be confused with adenoid cystic carcinoma or a cellular mixed tumor. The diversity of growth patterns and lack of dark-staining tumor cells support the diagnosis of PLGA and usually allow separation from adenoid cystic carcinoma, which has tubular, cribriform, and solid growth patterns. The majority of mixed tumors will have at least a focal mesenchymelike component consisting of cartilage or a myxoid background or both, and foci with plasmacytoicl myoepithelial cells, allowing proper classification (12). Surgical resection with an appropriate safety margin is the treatment of choice. Elective neck dissection is not warranted unless the patient shows clinical evidence of lymph node metastasis. Historically, radiotherapy has been recommended for PLGA with inadequate margins, perineural or perivascular spread, and/or lymph node involvement (13). In our case surgery was impossible, but the patient felt discomfort and heaviness in the left side of her face and insisted on receiving some kind of treatment. Therefore, we decided to try radiation therapy. Castle et al. (14) reviewed 164 cases of PLGA and in that group 17 patients received radiation therapy after incisional or excisional biopsy or wide excision. The patients who had received radiation therapy were more likely to show evidence of 

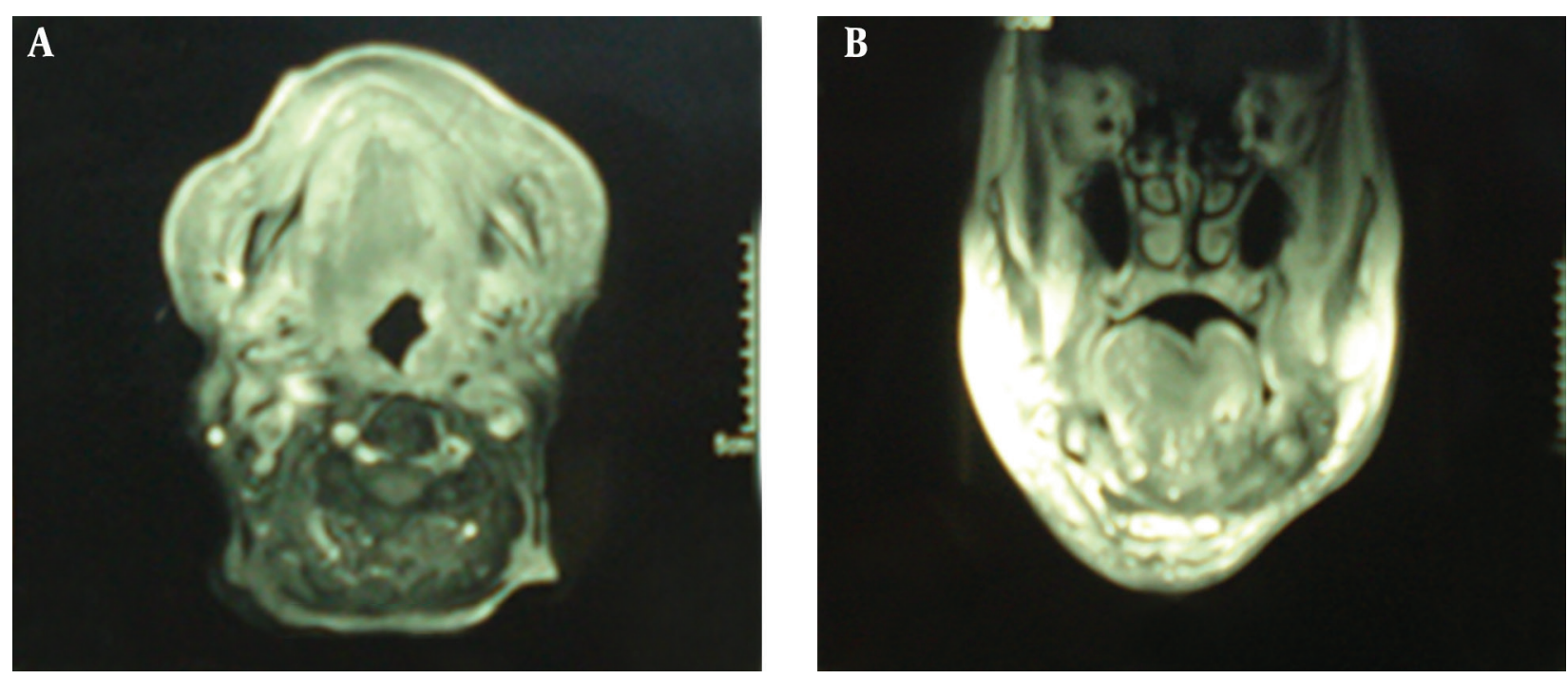

Figure 3. MRI After Termination of Radiation Therapy Showed an Excellent Tumor Response

disease at their last follow-up; however, the overall survival rate was not statistically different from those who did not receive radiation. In another case report Makita et al. (15) reported a patient with PLGA of palate who refused surgery and was instead treated with intra-arterial cisplatin and proton beam therapy and showed disease control. Uemaetomari et al. (16) presented two cases of PLGA who received post-operative radiation and concluded that radiation therapy possibly helps to improve local control. However, Evans (17) found no significant differences in the rates of regional metastases, distant metastasis, and patient survival according to the type of initial therapy or margin status. Since PLGA is uncommon, there is no clear recommendation for elective neck irradiation; however, as our patient had an advanced disease, we decided to treat at least levels I and II and upper part of level III. It should be noted that late recurrences, metastases, and fatal outcomes, though currently infrequent, may not be as rare as previously thought. There are some reports of transformation to a higher-grade tumor (18), and these patients have a less favorable clinical outcome. Since there can be protracted periods of time between initial resection and recurrence, a long-term follow-up is needed.

\section{References}

1. Furuse C, Tucci R, Machado de Sousa SO, Rodarte Carvalho Y, Cavalcanti de Araujo V. Comparative immunoprofile of polymorphous low-grade adenocarcinoma and canalicular adenoma. Ann Diagn Pathol. 2003;7(5):278-80.

2. Darling MR, Schneider JW, Phillips VM. Polymorphous lowgrade adenocarcinoma and adenoid cystic carcinoma: a review and comparison of immunohistochemical markers. Oral Oncol. 2002;38(7):641-5.

3. Nagao T, Gaffey TA, Kay PA, Minato H, Serizawa H, Lewis JE. Poly- morphous low-grade adenocarcinoma of the major salivary glands: report of three cases in an unusual location. Histopathology. 2004;44(2):164-71.

4. Miliauskas JR. Polymorphous low-grade (terminal duct) adenocarcinoma of the parotid gland. Histopathology. 1991; 19(6):555-7.

5. George MK, Mansour P, Pahor AL. Terminal parotid duct carcinoma. J Laryngol Otol. 1991;105(9):780-1.

6. Seifert G. Histological typing of salivary gland tumours. New York: Springer Science \& Business Media; 1991.

7. Batsakis JG, Pinkston GR, Luna MA, Byers RM, Sciubba JJ, Tillery GW. Adenocarcinomas of the oral cavity: a clinicopathologic study of terminal duct carcinomas. J Laryngol Otol. 1983;97(9):825-35.

8. Freedman PD, Lumerman H. Lobular carcinoma of intraoral minor salivary gland origin. Report of twelve cases. Oral Surg Oral Med Oral Pathol. 1983;56(2):157-66.

9. Ellis GL, Auclair PL. Polymorphous low-grade adenocarcinoma. Atlas of Tumor Pathology: Tumors of the Salivary Glands. Washington DC: Armed Forces Institute of Pathology; 1996. p. 216-228.

10. Luna MA, Wenig BM. Polymorphous low-grade adenocarcinoma. In: Barnes L, Eveson JW, Reichart P editors. Pathology and Genetics of Head and Neck Tumours World Health Organization Classification of Tumours: .. Lyon: IARC Press; 2005. p. 223-224.

11. Clayton JR, Pogrel MA, Regezi JA. Simultaneous multifocal polymorphous low-grade adenocarcinoma. Report of two cases. Oral Surg Oral Med Oral Pathol Oral Radiol Endod. 1995; $\mathbf{8 0}(1): 71-7$.

12. Gnepp RD, Henley DJ, Simpson HWS, Eveson J. Diagnostic Surgical Pathology of the Head and Neck. 2th edUSA: Elsevier Health Sciences; 2009.

13. Le QT, Birdwell S, Terris DJ, Gabalski EC, Varghese A, Fee WJ, et al Postoperative irradiation of minor salivary gland malignancies of the head and neck. Radiother Oncol. 1999;52(2):165-71.

14. Castle JT, Thompson LD, Frommelt RA, Wenig BM, Kessler HP. Polymorphous low grade adenocarcinoma: a clinicopathologic study of 164 cases. Cancer. 1999;86(2):207-19.

15. Makita C, Nakamura T, Takayama K, Takada A, Fuwa N, Sakuma $\mathrm{H}$. Proton beam therapy and continuous intra-arterial chemotherapy for polymorphous low-grade adenocarcinoma in the hard palate. Case Rep Oncol. 2013;6(1):66-71.

16. Uemaetomari I, Tabuchi K, Tobita T, Tsuji S, Wada T, Kamma H, et al The importance of postoperative radiotherapy against polymor- 
phous low-grade adenocarcinoma of the parotid gland: case report and review of the literature. TohokuJ Exp Med. 2007;211(3):297-302.

17. Evans HL, Luna MA. Polymorphous low-grade adenocarcinoma: a study of 40 cases with long-term follow up and an evaluation of the importance of papillary areas. Am J Surg Pathol.

\section{0;24(10):1319-28.}

18. Simpson RH, Pereira EM, Ribeiro AC, Abdulkadir A, Reis-Filho JS. Polymorphous low-grade adenocarcinoma of the salivary glands with transformation to high-grade carcinoma. Histopathology. 2002;41(3):250-9. 